\title{
IDENTIFICATION OF ROOT ROT PATHOGENS ISOLATED ON SPRING GRAIN CROPS IN REPUBLIC OF MORDOVIA
}

\section{M.I. KISELEVA ${ }^{1}$, N.S. ZHEMCHUZHINA ${ }^{1}$, V.P. DUBOVOI ${ }^{1}$, V.V. LAPINA ${ }^{2}$}

\author{
${ }^{1}$ All Russian Research Institute of Phytopathology, Federal Agency of Scientific Organizations, vl. 5, ul. Institut, pgt \\ Bol'shie Vyazemy, Odintsovo Region, Moscow Province, 143050 Russia, e-mail kiseleva@vniif.ru; \\ ${ }^{2}$ Institute of Agriculture of N.P. Ogarev Mordovia State University, 68, Bol'shevitskaya ul., Saransk, Republic of \\ Mordovia, 430005 Russia, e-mail van20099@mail.ru \\ Received December 26, 2014
}

\section{Abstract}

The root rot caused by fungi of Fusarium and Bipolaris genera has damaged both winter and spring cereals. The specific rang of the disease agents is characteristic to certain ecological and geographical areas. Root Rot symptoms on wheat (Triticum L.), rye (Secale cereale L.), oats (Avena L.) and barley (Hordeum L.) plants are similar. The soil is the basic source of the infection. Also mass infection has been transferred by seeds in the years of abundant precipitations. Pathogenic properties of the root rot agents is due to their ability to develop hydrolytic enzymes and toxins, such as helminthosporol, helminthosporal, victoxin in B. sorokiniana strains, isomarticin, zearalenone, diacetoxyscirpenol, nivalenol in Fusarium spp., etc. The Fusarium and Bipolaris species are facultative parasites. In the paper the study of fungal species causing root rot and leaf spot of cereals in the Republic Mordovia territory, and also pathogenic properties of widespread and infrequent Fusarium spp. has been represented. Damaged plants of spring wheat, barley and oats (a total of 38 cultivars) in heading stage were sampled. The infected leaves and roots were cut into fragments, aseptically sterilized and placed in Petri dishes on $2 \%$ potato-glucose agar. During growth, the mycelia slices were transferred on a new nutrient medium. As a result, the pure cultures were isolated and the morphology of their colonies were studied. For the evaluation of morphology uniformity of strains, we isolated not less than 20 single spore cultures of fungi using serial cultivations of spore suspensions. Pathogenic and toxic properties of Fusarium spp. and Bipolaris sp. strains were studied in biotest on seeds of susceptible wheat cultivar Mironovskaya 808. Finally, there were a total of 457 isolates of pathogenic and saprophytic fungi. No clear specialization of fungi species to cereals was shown. The several species of genera Fusarium ( F. heterosporum, F. sporotrichioides, F. oxysporum) and Bipolaris ( $B$. sorokiniana) prevailed on roots of wheat, barley and oat plants. Isolates of $F$. redolens, $F$. verticillioides, $F$. tricinctum were few. There were many accompanying saprophytic isolates allocated together with pathogenic fungi, such as Alternaria alternata, Mortierella elongata var. elongata, Papulaspora appendicularis, Clonostachys rosea f. catenulata, Acremonium strictum, Trichoderma hamatum, etc. As a result of monosporous selections, 24 strains of Fusarium spp. and Bipolaris sp. with stable morphology have been isolated. The wide rang of plant-hosts was found out for $F$. heterosporum, F. sporotrichioides, F. oxysporum and Bipolaris sorokiniana. The widespread species of fungi had various pathogenic and toxic properties, indicating their strong intraspecific variability. Rare fungal species possessed toxicity to test-plant seedlings, but were not pathogenic. This fact possibly explains their low frequency in the root rot mycobiota. B. sorokiniana strains were highly pathogenic and toxic to tests plants.

Keywords: root rots, Fusarium, Bipolaris, isolates, morphology of colonies, culture, pathogenicity, toxicity.

The root rot caused by Fusarium and Bipolaris fungi is known to be prevalent in various areas of cereal cultivation [1,2]. They infect both winter and spring cereals throughout the growing period [3], and the direct loss of grain is estimated at $20-50 \%$ and more $[4,5]$. The species composition of root rot pathogens is associated with specific ecological and geographic regions and is mixed, as a rule. Thus, fusarium helminthosporal root rot with predominance of Fusarium species is found in the areas of winter wheat cultivation, that is in the Central Black Earth and the North Caucasus regions, while Bipolaris sorokiniana is found mainly in spring crops in the non-Chernozem zone (North-West, Central, and Volga- 
Vyatka regions) $[6,7]$.

Root rots in wheat, rye, oats, and barley are manifested with similar symptoms $[8,9]$. This type of disease is characterized by uneven local spreading. The soil is the basic source of infection. In the years with abundant precipitation, infection transfer via seeds is intensified. Root rot epiphytoties are usually preceded by a long period of infection accumulation in the soil. Pathogenic properties of the root rot agents are due to their capability of developing hydrolytic enzymes and toxins, e.g., B. sorokiniana produces helminthosporol, helminthosporal, victoxin, and cytokinin; Fusarium produces isomarticin, zearalenone, diacetoxyscirpenol, nivalenol, etc. [10]. Fungal metabolites have toxic effects on the sprouts and shoots in the period of active mycelium growth [11, 12].

B. sorokiniana (Cochliobolus sativum Drechsl.) mycelium and conidia are the main forms of fungi reproduction, dissemination and dormancy when wintering [13]. In the spring, plant root and stem tissues are infested via the penetration of endogenous mycelium and germinating conidia. Damp weather promotes the development of conidial sporulation which looks as velvety plaque on the roots and plant residues. Conidia spread aerogenically or with raindrops to other plants, including the emerging ears. B. sorokiniana infects wheat and barley plants throughout the growing season, and the spores are formed in autumn and spring on stubble. Fungi persist as conidia and chlamydospores in the soil. They may produce pseudothecia with ascus and ascospores on the overwintered affected plant remnants [14].

Fusarium species ( $F$. culmorum, $F$. graminearum, $F$. heterosporum, $F$. avenaceum, $F$. oxysporum, $F$. solani, etc.) are the fusarium root rot pathogens [15]. With seed germination in rolls, a thin, fluffy, fast-growing snowwhite or bright-crimson mycelium develops [7, 16]. Formation of microconidia and macroconidia is characteristic of the fungi in this genus. Microconidia are unicellular, rarely with 1-2 septa, oval and egg-shaped; macroconidia have 3 to 9 septa, are of various shapes, sizes and curvatures. Most fungi species form colorless or brown unicellular chlamydospores or sclerotia [17]. Pathogenic Fusarium species may develop saprophytically on crop roots, but become parasitic with plant weakening so that they destroy the root system, and inhabit the tillering node and stem bases. Conidia are spread by air flow.

Root rot causal agents have a wide specialization, are capable of infecting not only cultivated and wild cereals, but also other families [4, 13, 18]. By the nature of their interactions with plants, Fusarium and Bipolaris species are facultative parasites. Wheat, rye, barley, and oat root rots cause very harmful diseases in cereals despite its hidden symptoms. In some cases, root rot can lead to almost total loss of plantings.

In recent years, cereal root rots have widely spread and cause considerable damage $[5,6]$. Failure to comply with crop rotation, monocultures of one or another cereal species, and low agricultural machinery create unfavorable conditions for plant growth and contribute to the accumulation of pathogenic fungi in the soil $[13,19]$. Root rot infections lead to the rotting of roots and root collar, resulting in the inhibition of growth, yellowing and drying of leaves, delayed ear formation, grain undersizing, and destruction of productive stems. A detailed study of Fusarium and Bipolaris species complex makes it possible to identify the environmental aspects of plasticity, confinement to specific climatic conditions, and trophic specialization in fungi.

The purpose of this work was to identify the fungal species that cause cereal root rot and leaf spot in the regions of the Republic of Mordovia, and to study the pathogenic properties of common and rare Fusarium species.

Technique. Spring wheat (Triticum L.), barley (Hordeum L.), and oats 
(Avena L.) samples (a total of 38 variety samples) were collected in 2011 in Chamzinka, Temnikovo, Dubyonky, Staroe Shaigovo, Atyur'evo and Elniky districts of the Republic of Mordovia (Middle Volga region of the Russian Federation) from industrial crops. The plants in the heading stage had the symptoms of leaf spots and root rot infestation.

Fungal pathogens were isolated as descibed [20]. Plant samples with the symptoms of infestation were thoroughly washed with water and dried on filter paper. The areas of infected tissues (leaves and roots) were cut into 3-7 mm fragments, sterilized in $50 \%$ alcohol for 1 minute and aseptically placed in Petri dishes on $2 \%$ potato-glucose agar, 4-5 cuts per dish. Petri dishes were placed in a thermostat at $22-24{ }^{\circ} \mathrm{C}$. The growth of fungi was daily recorded. With the growth, mycelium pieces were passed to a new growth medium in the centers of Petri dishes. As a result of 2-3 successive passages, pure cultures (isolates) were obtained and examined for the presence of spores for species identification using an Olympus CX41 microscope (Olympus Corporation, Japan) at $\times 850$. Species were identified using the V.I. Bilay [21], B.A. Khasanov [18], F.M. Dugan [22], W. Gerlach and H. Nirenberg [23], W.C. Snyder and H.N. Hansen [24], E.G. Simmons [25] keys. To evaluate the uniformity of morphological and cultural traits, at least 20 monoconidial fungal cultures were repassaged. Monoconidial cultures were obtained by subculturing serial spore suspension dilutions.

Pathogenic and phytotoxic properties of the strains were studied using seed bioassays [11]. The sprouts of wheat variety Mironovskaya 808 susceptible to all root rot pathogens were used as the host plant. To detect pathogenic properties, the tested plant seeds were germinated in conidia suspension $\left(10^{6}\right)$; to detect phytotoxicity, the seeds were treated with the medium filtrate. Pathogen strains were differentiated into four groups according to their pathogenicity and toxicity, i.e. nonpathogenic and nontoxic $(0-30 \%$ plant growth inhibition), low pathogenic and low toxic (31-50\% inhibition), moderately pathogenic and moderately toxic (51-70\% inhibition), and toxic and pathogenic (inhibition above $70 \%$ ).

Fungal isolate pathogenicity and toxicity were estimated by inhibition of germination, and by slowing down the sprout development and especially root development so far as the root length is the most informative indicator of diseases of this etiology. The root length in the seeds germinating in water (control) was taken as $100 \%$.

All experiments were performed in 3 replicates. Statistical processing was conducted using Microsoft Excel software package.

Results. In mycological studies, a total of 457 pathogenic and saprophytic fungi isolates of various species were obtained as pure cultures from infected roots and leaves of spring wheat, barley, and oats. No clear specialization of fungi species to cereals has been shown (Table 1).

Fusarium (F. heterosporum, F. sporotrichioides, F. oxysporum) and Bipolaris (B. sorokiniana) isolates were predominant among the hemibiotrophic fungi. $F$. redolens, $F$. verticillioides, and $F$. tricinctum species were low frequent. Along with pathogenic species, a large number of isolates belonging to concomitant microflora were isolated as pure cultures. These were saprophytic fungal species $A l-$ ternaria alternata (Fr.) Keissl., Mortierella elongata var. elongata Linnem., Papulaspora appendicularis H.H. Hotson, Clonostachys rosea f. catenulata (J.C. Gilman et E.V. Abbott) Schroers, Acremonium strictum W. Gams, Trichoderma hamatum (Bonord.) Bainier, etc.

The clones of pathogenic fungi species isolated from cereal leaves and roots had heterogeneous colony topography. To determine the morphological and 
1. Incidence of some fungi species isolated from cereals in the Republic of Mordovia (2011)

\begin{tabular}{|c|c|c|c|}
\hline Pathogen & Wheat & Barley & Oats \\
\hline Fusarium oxysporum & +++ & +++ & ++ \\
\hline F. heterosporum & +++ & +++ & ++ \\
\hline F. sporotrichioides & +++ & + & + \\
\hline$F$. redolens & - & + & - \\
\hline F. verticillioides & - & - & + \\
\hline F. tricinctum & - & - & + \\
\hline Bipolaris sorokiniana & +++ & +++ & + \\
\hline Alternaria sp. & +++ & +++ & +++ \\
\hline Arthrinium sp. & ++ & + & ++ \\
\hline Epicoccum sp. & ++ & ++ & ++ \\
\hline Trichoderma sp. & +++ & +++ & +++ \\
\hline Acremonium strictum & +++ & +++ & ++ \\
\hline
\end{tabular}

2. Fusarium and Bipolaris strains isolated from infested cereal samples in the Republic of Mordovia (2011)

\begin{tabular}{|c|c|c|c|}
\hline Isolate & Species & Origin & Symptoms \\
\hline \multicolumn{4}{|c|}{ Spring wheat } \\
\hline RMDsug-1k/3 & F. heterosporum & Dubyonky district & Root rot \\
\hline RMDsug-1k/11 & F. heterosporum & Dubyonky district & Root rot \\
\hline RMD-4k/4 & B. sorokiniana & Dubyonky district & Root rot \\
\hline RMA-6l/5 & F. sporotrichioides & Atyur'evo district & Leaf spot \\
\hline \multirow{2}{*}{\multicolumn{4}{|c|}{ Spring barley }} \\
\hline & & & \\
\hline $\mathrm{RMCh}-2 \mathrm{k} / 2$ & F. heterosporum & Chamzinka district & Root rot \\
\hline $\mathrm{RMCh}-2 \mathrm{k} / 3$ & F. heterosporum & Chamzinka district & Root rot \\
\hline RMT-3k/2 & F. heterosporum & Temnikovo district & Root rot \\
\hline RMD-3k/1 & F. heterosporum & Dubyonkydistrict & Root rot \\
\hline RMCh-2k/4 & F. oxysporum & Chamzinka district & Root rot \\
\hline RME-5k/1 & F. oxysporum & Elniky district & Root rot \\
\hline $\mathrm{RME}-5 \mathrm{k} / 3$ & F. oxysporum & Elniky district & Root rot \\
\hline RMA-7k/1 & F. oxysporum & Atyur'evo district & Root rot \\
\hline $\mathrm{RMT}-4 \mathrm{k} / 1$ & $F$. redolens & Temnikovo district & Root rot \\
\hline RMK-2k/1 & B. sorokiniana & Krasnoslobodsk district & Root rot \\
\hline RMD-31/1 & F. heterosporum & Dubyonkydistrict & Leaf spot \\
\hline RMTem-31/2 & F. heterosporum & Temnikovo district & Leaf spot \\
\hline RMA-71/1 & F. oxysporum & Atyur'evo district & Leaf spot \\
\hline RMK-2l/2 & B. sorokiniana & Krasnoslobodsk district & Leaf spot \\
\hline RMT-4l/1 & B. sorokiniana & Torbeevo district & Leaf spot \\
\hline RME-5l/2 & B. sorokiniana & Elniky district & Leaf spot \\
\hline RME-5l/4 & B. sorokiniana & Elniky district & Leaf spot \\
\hline \multicolumn{4}{|c|}{ Spring oats } \\
\hline RMS-1k/1 & F. verticillioides & Staroe Shaigovo district & Root rot \\
\hline RMS- $1 \mathrm{k} / 7$ & F. tricinctum & Staroe Shaigovo district & Root rot \\
\hline
\end{tabular}
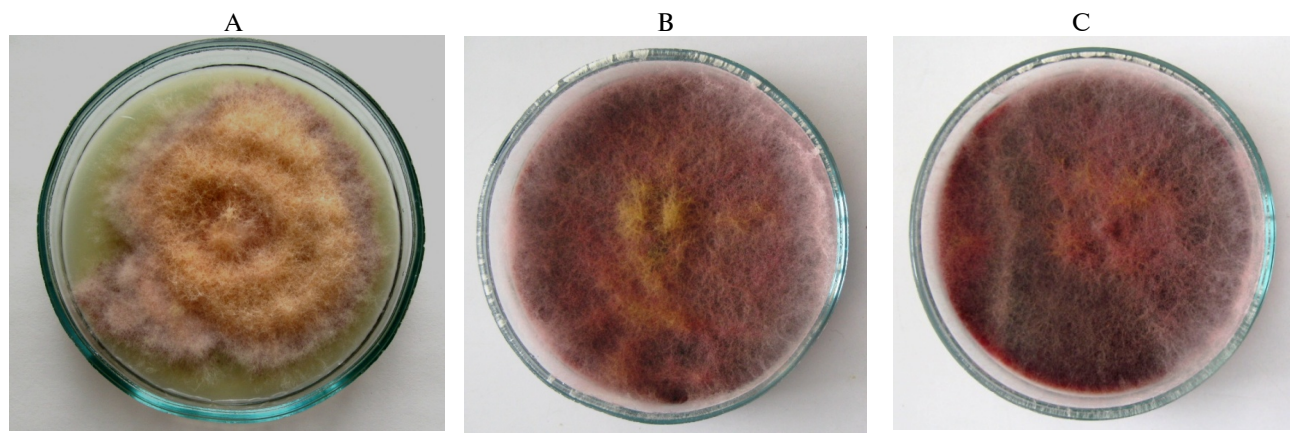

Fig. 1. Fusarium sporotrichioides isolates from wheat (Triticum aestivum L.) plant roots cultured on $2 \%$ potato-glucose agar: A - fungus clone unstable for morphological and cultural features, B mono-spore culture of RMA-61/2, C - mono-spore culture of RMA-61/5.

cultural characteristics in the populations of various fungal species, to select the strains stable for these traits and to study their pathogenic and toxic properties, isolated clones were subjected to conidial selection. As a result of 2-3 mono-spore 
selections, 24 Fusarium and Bipolaris fungal strains characterized by stable morphological and cultural features were obtained (Table 2).

Typically, morphological and cultural features of pure culture fungal colonies (clones) isolated from the samples of infested plants differed from those subjected to mono-spore selection. Thus, F. sporotrichioides clones formed the colonies with inhomogeneous mycelium and uneven edges; sectors with different types of mycelium emerged frequently. Mono-spore culture colonies (strains RMA-61/2 and RMA-61/5) had homogeneous mycelium texture, and mycelium was pink, raised by the middle (Fig. 1).
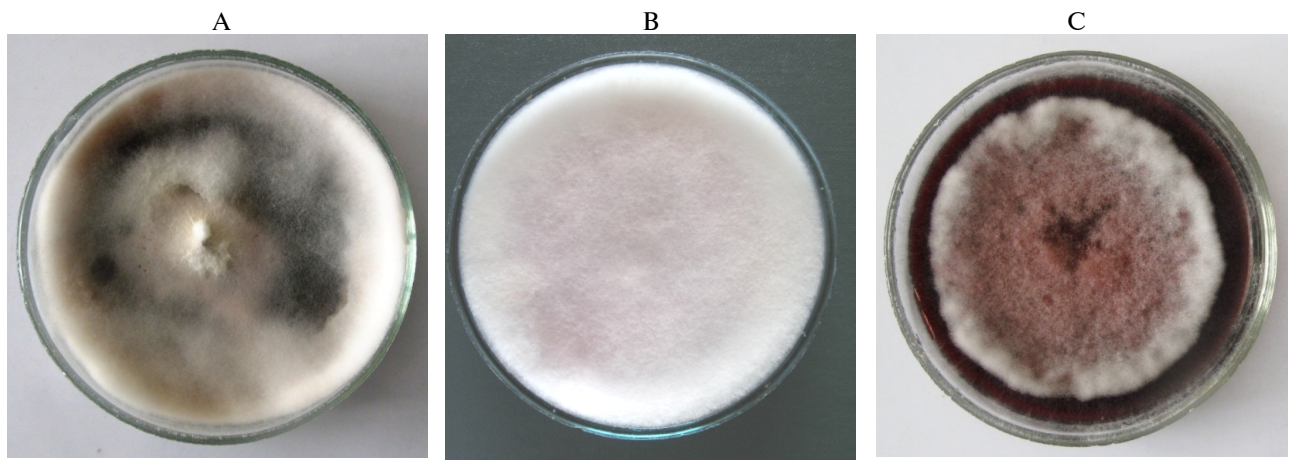

Fig. 2. Fusarium oxysporum isolates from wheat (Triticum aestivum L.) plant roots cultured on $2 \%$ potato-glucose agar: A - fungus clone unstable for morphological and cultural features, B - monospore culture of RME-5k/3, C - mono-spore culture of RMA-7k/1.

This was characteristic of $F$. oxysporum as well. Fungal isolates from infested roots and leaves formed colonies with mycelium uneven in topography, often with membranous and zones of lysis. After 2-3 mono-spore selections, fungal strains usually formed the colonies of homogeneous consistency and color, e.g. white arachnoid mycelium with purple (or olive) inclusions, or stocky burgundy mycelium (Fig. 2). The presence of colonies with different morphological and cultural properties was characteristic of some $F$. heterosporium strains even after repeated conidial selections. Thus, most mono-spore colonies of strains RMCh-2k/2 and RMTem-3l/2 had abundant mycelium of a cream shade, but white homogeneous mycelium was observed in 10-20\% colonies (Fig. 3).

A

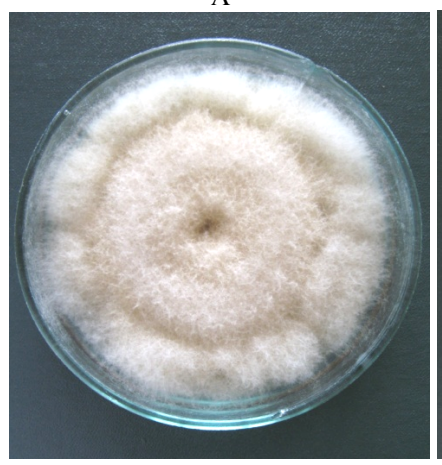

B

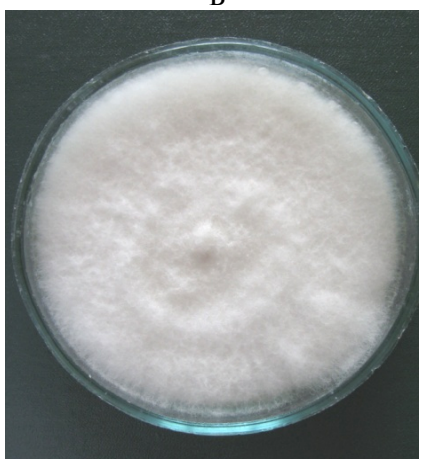

Fig. 3. Mono-spore strain Fusarium heterosporum colonies grown on $2 \%$ potato-glucose agar: A - RMDsug-1k/11 isolated from wheat roots, $\mathrm{B}-\mathrm{RMD}-3 \mathrm{k} / 1$ isolated from barley roots.

black in both cases (Fig. 4).

The diversity of fungal colonies for morphological and cultural properties within the species depended largely on the genetic peculiarities of multicellular conidia pathogens. It should be noted that morphological traits of mono-conidial polaris sorokiniana colonies was typical for the species. Fungal isolates from the roots of cereals usually formed inhomogeneous abundant gray colonies, often containing black sectors. Fungal strains obtained after a series of mono-spore selection had black, smooth, velvety mycelium consisting of conidia plaque. The colony reverse side was 
culture colonies of the same species were not associated with fungal specialization. Thus, strain $F$. heterosporum colonies isolated from wheat (PMDsug-1k/3, PMDsug-1k/11) and barley (RMCh-2k/2, RMCh-2k/3, RMT-3k/2) roots had similar morphological and cultural features on $2 \%$ potato-glucose agar. Within a species, fungal strains were characterized by high mono-conidial isolate colony heterogeneity for morphological and cultural features (80-100\%).
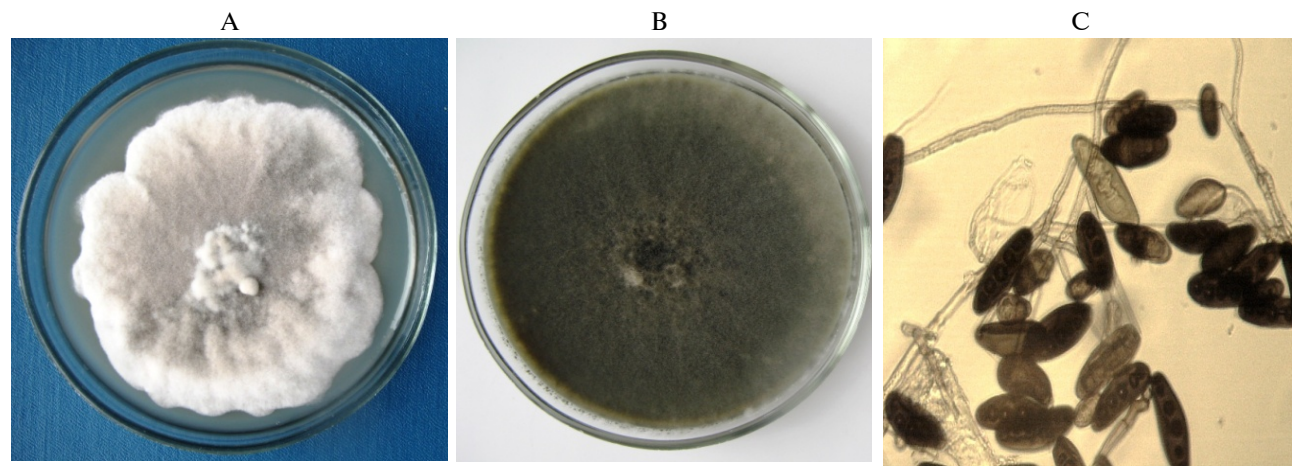

Fig. 4. Bipolaris sorokiniana isolates from barley (Hordeum vulgare L.) plant roots cultured on $2 \%$ potato-glucose agar: A - fungal clone unstable for morphological and cultural features, B - monospore culture; $\mathrm{C}-$ strain RME-51/2 conidia ( $\times 850$, Olympus CX41 microscope, Japan).

3. Characterization of Fusarium spp. and Bipolaris sp. strains isolated from various crops for their pathogenicity and phytotoxicity on the sprouts of the susceptible test variety Mironovskaya 808

\begin{tabular}{|c|c|c|c|c|c|c|c|c|c|}
\hline \multirow{3}{*}{ Isolate } & \multirow{3}{*}{$\mathrm{C}$} & \multicolumn{4}{|c|}{ Pathogenicity } & \multicolumn{4}{|c|}{ Toxicity } \\
\hline & & \multirow{2}{*}{ GA } & \multicolumn{2}{|c|}{ length, $\mathrm{mm}(X \pm X)$} & \multirow{2}{*}{ PD } & \multirow{2}{*}{ GA } & \multicolumn{2}{|c|}{ length, $\mathrm{mm}(X \pm X)$} & \multirow{2}{*}{ PD } \\
\hline & & & germs & roots & & & germs & roots & \\
\hline \multicolumn{10}{|c|}{ F. heterosporum } \\
\hline RMDsug- $1 \mathrm{k} / 3$ & Wheat & 100.0 & $105.3 \pm 3.3$ & $84.4 \pm 3.4$ & NP* & 96.7 & $31.4 \pm 2.5$ & $24.1 \pm 2.0$ & $\mathrm{~T}$ \\
\hline RMDsug-1k/11 & 1Wheat & 46.2 & $26.8 \pm 12.1$ & $26.6 \pm 10.0$ & $\mathrm{P}$ & 42.9 & $27.9 \pm 13.8$ & $8.7 \pm 3.6$ & $\mathrm{~T}$ \\
\hline RMCh-2k/2 & Barley & 109.4 & $95.0 \pm 3.8$ & $77.7 \pm 3.5$ & NP & 90.0 & $38.7 \pm 4.7$ & $21.3 \pm 2.3$ & $\mathrm{~T}$ \\
\hline RMCh-2k/3 & Barley & 103.5 & $100.7 \pm 3.0$ & $64.6 \pm 2.5$ & LP & 95.0 & $9.8 \pm 1.0$ & $6.5 \pm 0.7$ & $\mathrm{~T}$ \\
\hline RMT-3k/2 & Barley & 103.4 & $104.8 \pm 4.2$ & $77.9 \pm 3.8$ & NP & 93.3 & $16.7 \pm 2.0$ & $12.8 \pm 1.6$ & $\mathrm{~T}$ \\
\hline RMD-3k/1 & Barley & 30.8 & $15.8 \pm 10.3$ & $17.8 \pm 8.8$ & $\mathrm{P}$ & - & - & - & \\
\hline RMD-3l/1 & Barley & 103.4 & $113.7 \pm 3.9$ & $95.6 \pm 3.3$ & NP & 86.7 & $28.8 \pm 2.7$ & $12.7 \pm 1.2$ & $\mathrm{~T}$ \\
\hline RMTem-31/2 & Barley & 61.5 & $40.6 \pm 14.2$ & $33.7 \pm 10.3$ & MP & 114.3 & $99.6 \pm 16.3$ & $44.8 \pm 6.8$ & MT \\
\hline \multicolumn{10}{|c|}{ F. oxysporum } \\
\hline RMCh-2k/4 & Barley & 66.7 & $63.1 \pm 4.3$ & $54.7 \pm 11.4$ & LP & 93.8 & $31.3 \pm 5.6$ & $7.0 \pm 1.4$ & $\mathrm{~T}$ \\
\hline RME-5k/1 & Barley & 100.0 & $109.3 \pm 6.4$ & $114.2 \pm 5.2$ & NP & 81.3 & $21.3 \pm 3.5$ & $15.7 \pm 3.8$ & $\mathrm{~T}$ \\
\hline RMA-7k/1 & Barley & 50.0 & $54.1 \pm 5.9$ & $49.5 \pm 2.7$ & MP & 93.8 & $11.6 \pm 2.4$ & $4.9 \pm 0.3$ & $\mathrm{~T}$ \\
\hline \multirow{2}{*}{\multicolumn{10}{|c|}{ F. sporotrichiodes }} \\
\hline & & & & & & & & & \\
\hline RMA-61/5 & Wheat & 15.4 & $3.1 \pm 2.2$ & $\begin{array}{c}1.2 \pm 0.8 \\
\text { F. redolens }\end{array}$ & $P$ & 42.9 & $17.7 \pm 7.9$ & $4.3 \pm 2.1$ & $\mathrm{~T}$ \\
\hline RMT-4k/1 & Barley & 69.2 & $85.9 \pm 3.0$ & $\begin{array}{c}88.5 \pm 3.4 \\
\text { F. verticiloides }\end{array}$ & NP & 100.0 & $79.1 \pm 6.4$ & $49.6 \pm 9.5$ & MT \\
\hline RMS-1k/1 & Oats & 100.0 & $106.8 \pm 4.5$ & $\begin{array}{c}91.0 \pm 2.9 \\
\text { F. } \text { tricinctum }\end{array}$ & NP & 103.4 & $29.6 \pm 2.1$ & $24.2 \pm 3.0$ & $\mathrm{~T}$ \\
\hline RMS-1k/7 & Oats & 69.6 & $64.3 \pm 9.7$ & $\begin{array}{c}73.2 \pm 9.8 \\
\text { B. sorokiniana }\end{array}$ & NP & 30.0 & $1.3 \pm 0.6$ & $3.2 \pm 1.3$ & $\mathrm{~T}$ \\
\hline RMD-4k/4 & Wheat & 46.2 & $4.6 \pm 2.5$ & $13.3 \pm 2.1$ & $P$ & 62.1 & $20.1 \pm 2.5$ & $13.8 \pm 2.2$ & $\mathrm{~T}$ \\
\hline RMA-61/2 & Wheat & 34.6 & $10.7 \pm 1.9$ & $17.8 \pm 2.7$ & $P$ & 71.4 & $6.7 \pm 3.8$ & $8.5 \pm 0.9$ & $\mathrm{~T}$ \\
\hline RMK-2k/1 & Barley & 42.3 & $10.0 \pm 1.9$ & $18.9 \pm 2.6$ & $P$ & 75.0 & $13.2 \pm 2.3$ & $12.2 \pm 2.2$ & $\mathrm{~T}$ \\
\hline RMK-2l/2 & Barley & 61.5 & $18.4 \pm 1.5$ & $11.1 \pm 2.4$ & $\mathrm{P}$ & 7.1 & $1.0 \pm 0.5$ & $0.8 \pm 0.3$ & $\mathrm{~T}$ \\
\hline RMT-4l/1 & Barley & 57.7 & $36.4 \pm 2.8$ & $25.5 \pm 5.3$ & $P$ & 60.0 & $22.2 \pm 4.1$ & $10.1 \pm 1.7$ & $\mathrm{~T}$ \\
\hline RME-5l/2 & Barley & 20.7 & $5.3 \pm 3.9$ & $1.3 \pm 3.5$ & $\mathrm{P}$ & 64.3 & $15.7 \pm 2.9$ & $14.4 \pm 2.7$ & $\mathrm{~T}$ \\
\hline RME-5l/4 & Barley & 34.5 & $12.1 \pm 3.1$ & $8.1 \pm 2.7$ & $P$ & 27.6 & $7.6 \pm 3.6$ & $5.1 \pm 3.1$ & $\mathrm{~T}$ \\
\hline
\end{tabular}

Fusarium and Bipolaris strains are known to have intraspecific variability, which largely determines pathogenesis in this group of fungi. We have studied pathogenic and phytotoxic properties of common (B. sorokiniana, F. hetero- 
sporum, F. oxysporum, F. sporotrichiodes) and rare ( $F$. redolens, $F$. verticiloides, $F$. tricinctum) fungal species (Table 3 ).

The wide range of plant hosts - wheat, barley, oats - was typical for the first ones. Almost all hemibiotrophic species strains were toxic to the test seedlings. The nature of pathogenic properties in common Fusarium species strains was controversial indicating their strong intraspecific variability for the studied features. The strains of rare fungal species were toxic but nonpathogenic to the test seedlings, which may explain their low frequency in the root rot mycobiota. Of all fungal species studied, B. sorokiniana strains only were highly pathogenic and toxic to test plants.

Thus, mycological studies of root parts in wheat, barley, and oats harvested from industrial crops in the Republic of Mordovia made it possible to determine the species composition of the major pathogens of root rot which belong to Bipolaris sorokiniana, Fusarium heterosporum, F. sporotrichioides, F. oxysporum, $F$. redolens, $F$. verticillioides, $F$. tricinctum, and $B$. sorokiniana species. $F$. redolens, $F$. verticillioides, and $F$. tricinctum species were rare. The clones of pathogenic fungal species isolated from the roots or leaves of cereals, and the strains of the same species resulting from mono-spore selection, differed in their colony topography. The first ones had uneven edges with the sectors of different consistencies mycelium, while even growth and homogeneous mycelium were typical for the second ones. As a result of successive mono-conidial selection, 24 Fusarium and Bipolaris fungal strains characterized by stable morphological and cultural properties were isolated. The features of the same species strains isolated from various cereals did not differ on $2 \%$ potato agar. Host-related specialization (wheat, barley, oats) of the B. sorokiniana, $F$. heterosporum, $F$. sporotrichiodes and $F$. oxysporum strains has been identified. Perhaps this is due to their high prevalence in hemibiotrophic populations which persist in the soil, on the roots of weeds and in many crop residues. The frequency of isolates of helminthosporal root rot and brown leaf spot caused by $B$. sorokiniana in all the plant crop samples studied was the highest. This prevalence of $B$. sorokiniana isolates is due to the high toxicity and pathogenicity of this fungus for various cereals.

\section{REFEREN CES}

1. K istle r H.C. Evolution of host specificity in Fusarium oxysporum. APS Press, St. Paul, Minnesota, 2001: 70-96.

2. Windels C.E. Economic and social impacts of Fusarium head blight: Changing farms and rural communities in the Northern Great Plains. Phytopathology, 2000, 90: 17-21 (doi: 10.1094/PHYTO.2000.90.1.17).

3. Kovalenko E.D., K is e leva M.I., Solo m at i n D.A. Agrokhimiya, 2002, 7: 67-74.

4. Ale k h i n V.T. Zashchita $i$ karantin rastenii, 2006, 5: 7-10.

5. S a n i n S.S., N a z a r o v a L.N. Zashchita i karantin rastenii, 2010, 2: 70-87.

6. C hulk in a V.I. Kornevye gnili khlebnykh zlakov $v$ Sibiri [Root rots of cereals in Siberia]. Novosibirsk, 1985.

7. K is e leva M.I., Kovale nko E.D. Barley Root Rot agents in different areas of Russia. APS/SON Joint Meeting (July 28-August 1, 2007, San Diego, USA). APS Meeting Abstracts. Phytophatology, 97(7): 57.

8. Zhemchuzhina N.S., Kise leva M.I., Abramova S.L., Makarov A.A. Zashchita $\mathrm{i}$ karantin rastenii, 2014, 1: 48-50.

9. Kiseleva M.I., Zhemchuzhina N.S., Kovalenko E.D., Dubovoi V.P., M a k a r ov A.A. Zashchita i karantin rastenii, 2014, 1: 50-52.

10. Wi ng N., B u rges s L.W., B ry d e n W.L. Cultural degeneration in two Fusarium species and its effects on toxicity and cultural morphology. Mycological Research, 1995, 99: 615-620 (doi: 10.1016/S0953-7562(09)80721-1).

11. Parfe nova T.A., A le k s e e a T.P. Mikologiya i fitopatologiya, 1995, 29(1): 78-82.

12. Mesterhazy A. Comparative analysis of artificial inoculation methods with Fusarium spp. on winter wheat varieties. Phytopath. Z., 1978, 93: 12-25. 
13. L e vit i n M.M., T y u t e r e v S.L. Zashchita i karantin rastenii, 2003, 11: 48.

14. S h o e m a k e r R.A. Nomenclature of Drechslera and Bipolaris, grass parasites segregated from Helminthosporium. Can. J. Bot., 1959, 37(5): 879-887 (doi: 10.1139/b59-073).

15. W a t a $\mathrm{n}$ a b e T. Pictorial atlas of soil and seed fungi. Morphologies of cultured fungi and key to species. CRC Press, NY, 2010.

16. S a mokhi na I.Ju., Kovale nko E.D., S rizhe k o z i n Ju.A. Variability of Fusarium culmorum - agent of Head Blight. Annual Meeting of the Phytopathological Society. Quebec City, Canada, 2006: 102.

17. Les li e J.F., B rett A. Summerell. The Fusarium laboratory manual. Blackwell Publishing, Ames Iowa, USA, 2006.

18. K h a s a n o v B.A. Opredelitel' gribov vozbuditelei «gel'mintosporiozov» rastenii iz rodov Bipolaris, Drechslera i Exserohilum [Fungi Bipolaris, Drechslera and Exserohilum as causal agents of helmintospoeiosis: manual of systematic mycology]. Tashkent, 1992.

19. Gargouri-Kammoun L., Gargouri S., Rezgui S., Bahri N., Hajlaoui M.R. Pathogenicity and aggressiveness of Fusarium and Microdochium on wheat seedlings under controlled conditions. Tunisian J. Plant Pathol., 2009, 4: 135-144.

20. Dudk a I.A. Metody eksperimental'noi mikologii [Methods of experimental mycology]. Kiev, 1982.

21. B il a i V.I. Mikroorganizmy - vozbuditeli boleznei rastenii [Microbial phytopathogens]. Kiev, 1988.

22. D u g a n F.M. The identification of fungi. All illustrated introduction with keys, glossary, and guide to literature. The American Phytopathological Society, St. Paul, Minnesota, USA, 2008.

23. G e rla $\mathrm{ch}$ W., Ni re n berg H. The genus Fusarium - a pictorial atlas. Mitteilungen der Biologischen Bundesanstalt für Land- und Forstwirtschaft, 1982, 209: 1-406.

24. S n y d e r W.C., H a n s e n H.N. Advantages of natural media and environments in the culture of fungi. Phytopathology, 1947, 37: 420-421.

25. S i m m o n s E.G. Alternaria. An identification manual. Utrecht, CBS, 2007. 